\title{
Ultrastructural Analysis of in Vitro Adherence and Production of Acid Proteases by Clinical Isolates of Candida parapsilosis Sensu Stricto Following Growth in the Presence of Keratinous Substrates from Human Source
}

\author{
Ana Flávia L. Specian ${ }^{1}$, Luciana Furlaneto-Maia ${ }^{2}$, Célia G. T. J. Andrade \\ Marcia Cristina Furlaneto ${ }^{*}$ \\ ${ }^{1}$ Department of Microbiology, Paraná State University at Londrina, Londrina, Brazil \\ ${ }^{2}$ Technological Federal University of Paraná, Londrina, Brazil \\ ${ }^{3}$ Electronic Microscopy and Microanalysis Laboratory, Paraná State University at Londrina, Londrina, Brazil \\ Email: "furlaneto@uel.br
}

Received September 25, 2013; revised October 25, 2013; accepted November 2, 2013

Copyright (C) 2013 Ana Flávia L. Specian et al. This is an open access article distributed under the Creative Commons Attribution License, which permits unrestricted use, distribution, and reproduction in any medium, provided the original work is properly cited.

\begin{abstract}
Candida parapsilosis is an increasingly important human pathogen. However, little is known about its potential to cause disease. The aims of the present study were to analyse the production of acid proteinases by clinical isolates of $C$. parapsilosis in the presence of different keratinous substrates from human sources (stratum corneum, nail and hair) and to verify the capability of yeast cells to adhere and grow as biofilm on these substrates. By scanning electron microscopy, it was observed that all C. parapsilosis sensu stricto isolates adhered to the keratinous substrates. For the isolate recovered from onychomycosis, the cell population attached to stratum corneum and hair keratin consisted mainly of blastoconidia. Differently, on nail keratin, pseudohyphae production was observed. Overall, there was a loose association between yeast cells and keratinous substrates. However, on stratum corneum, flocculent extracellular material was seen evolving cells from the onychomycosis isolate by forming a biofilm-like structure. The isolates recovered from onychomycosis and cutaneous lesion produced higher amount of acid proteinases in medium supplemented with nail keratin and stratum corneum keratin, respectively, than that in salt medium (absence of keratin). Furthermore, no differences were observed in the amount of acid proteinases produced by the isolate recovered from tracheal secretion in the media tested (absence and presence of keratin substrates). The information derived from this study will further our understanding of acid proteinase production by C. parapsilosis isolates and provide an insight into pathogenic mechanisms in C. parapsilosis particularly from isolates recovered from superficial mycoses.
\end{abstract}

Keywords: Adherence; Keratinic Substrates; SEM; Acid Proteinase

\section{Introduction}

Candida parapsilosis is an opportunistic yeast pathogen that colonizes human skin and can spread nosocomially through hand carriage $[1,2]$. Over the past decade, the incidence of C. parapsilosis has dramatically increased. The yeast can cause candidiasis that can vary from relatively mild skin mycoses to life-threatening systemic or disseminated disease (reviewed in van Asbeck et al. [3]).

Concerning superficial mycoses, C. parapsilosis has gained increasing recognition worldwide as the most

\footnotetext{
"Corresponding author.
}

common etiological agent causing Candida onychomycosis (reviewed in Trofa et al. [4]). In Brazil, C. parapsilosis is the first or second most common cause of onychomycosis lesions [5-8]. For C. parapsilosis the colonized normal skin presumably serves as a reservoir of infection for the nails. Recently, we showed the capability of $C$. parapsilosis isolates exhibiting distinct phenotypes to grow as biofilm on human nail surfaces [9].

Several virulence factors of $C$. parapsilosis have been proposed, including adhesion, biofilm formation and secretion of hydrolases such as secreted aspartic proteinases (Saps) (reviewed in Trofa et al. [4]). We previ- 
ously reported the production of proteinases and haemolytic factor by isolates of $C$. parapsilosis obtained from distinct clinical sources [10]. More recently, we have demonstrated that $C$. parapsilosis sensu stricto secretes a hemolytic factor into culture medium [11].

However, in contrast to the species Candida albicans, virulence traits of $C$. parapsilosis have not been extensively studied. Few studies have been undertaken to evaluate the adhesion ability of clinical strains of $C$. parapsilosis [9,12-14]. Furthermore, the relationship between $C$. parapsilosis virulence and proteinase phenotype is still unclear.

In this study, we investigated for the first time the in vitro adherence pattern and production of acid proteases by clinical isolates of $C$. parapsilosis in the presence of keratinous substrates from human source, e.g., stratum corneum, nail and hair.

\section{Materials and Methods}

\subsection{Candida Isolates and Identification}

Isolates of $C$. parapsilosis sensu stricto included in this study were recovered from fingernail onychomycosis (isolate 150.06), cutaneous candidiasis (isolate 220.07) and tracheal secretion (isolate 205.06) [15]. The identity of isolates was determined by the PCR technique as described by França et al. [10] using C. parapsilosis (formerly C. parapsilosis group I) specific primers for URA3 gene (orotidine-5'-phosphate decarboxylase) [16] that allows to distinguish $C$. parapsilosis sensu stricto from the cryptospecies belonging to the $C$. parapsilosis complex.

\subsection{Preparation of Keratin Substrates}

For the substrate stratum corneum, fragments of human sole from healthy volunteer were prepared as described previously [17] with modifications. The fragments were soaked in ethanol for $96 \mathrm{~h}$ following washes with sterilized distillated water until a clean solution was obtained. The fragments were dried at $50^{\circ} \mathrm{C}$, grounded to a powder in liquid nitrogen and dried again at $50^{\circ} \mathrm{C}$.

The substrates nail and hair were prepared as described previously [18] with modifications. Human's hair and nail from healthy volunteer were cut to obtain small fragments ranging from 0.5 to $1 \mathrm{~cm}$ of size. The fragments were defatted by soaking for $4 \mathrm{~d}$ in chloroformmethanol 1:1 (v/v). The solvent was changed once a day. The fragments were then thoroughly washed with sterilized distillated water and dried for $3 \mathrm{~d}$ at $50^{\circ} \mathrm{C}$. The nails fragments were grounded to a powder in presence of liquid nitrogen and dried again at $50^{\circ} \mathrm{C}$. The prepared substrates were autoclaved for $5 \mathrm{~min}$ at $115^{\circ} \mathrm{C}$ and then added to previously sterilized basal minimal medium.

\subsection{Growth Profiles Determination and Proteinase Production}

The isolates were pre-cultured in Sabouraud dextrose $(4 \%$ dextrose, $1 \%$ peptone, $1 \%$ yeast extract) liquid medium and grown in submerged culture $(180 \mathrm{rpm})$ at $37^{\circ} \mathrm{C}$ for 18 h. For enzyme production, cell suspensions $\left(10^{4}\right.$ cells $\left./ \mathrm{ml}\right)$ were inoculated in basal minimal medium (MM) [19], with modifications, containing $(\mathrm{g} / \mathrm{l}): \mathrm{K}_{2} \mathrm{HPO}_{4}-1.5 \mathrm{~g}$; $\mathrm{MgSO}_{4} \cdot 7 \mathrm{H}_{2} \mathrm{O}-0.025 \mathrm{~g} ; \mathrm{CaCl}_{2}-0.025 \mathrm{~g} ; \mathrm{FeSO}_{4} \cdot 7 \mathrm{H}_{2} \mathrm{O}-$ $0.015 \mathrm{~g}, \mathrm{ZnSO}_{4} \cdot 7 \mathrm{H}_{2} \mathrm{O}-0.005 \mathrm{~g}$ and $1 \%$ glucose, and $\mathrm{MM}$ amended with either $0.5 \%(\mathrm{w} / \mathrm{v})$ stratum corneum, hair and nail $(\mathrm{MM}+\mathrm{SC}, \mathrm{MM}+\mathrm{H}$ and $\mathrm{MM}+\mathrm{N}$, respectively) and grown in submerged culture (180 rpm) at $37^{\circ} \mathrm{C}$ for up to 10 days. Media were buffered using a citrate buffer ( $0.1 \mathrm{M}$ citric acid; $0.1 \mathrm{M}$ sodium citrate), $\mathrm{pH}$ 5.0. Following growth, yeast cells were harvested by centrifugation at $8000 \mathrm{~g}$ for $20 \mathrm{~min}$ at $4^{\circ} \mathrm{C}$. The supernatants obtained were stored at $-20^{\circ} \mathrm{C}$ and assayed for protease activity. For growth rate assessment samples were removed at 12-h intervals. The growth rate was determined by haemocytometric counts. All experiments were repeated three times, and the results represent mean values $\pm \mathrm{SD}$.

\subsection{Proteinase Assay}

Proteolytic activity was determined as previously described [20] with modifications, using haemoglobin (Sigma; St. Louis, MO) as substrate. Each assay included $50 \mu \mathrm{l}$ of culture supernatant and $0.2 \mathrm{ml}$ of $20 \mathrm{mM}$ citrate buffer, $\mathrm{pH} 4.0$, containing haemoglobin $(0.5 \mathrm{mg} / \mathrm{ml})$. After incubation at $37^{\circ} \mathrm{C}$ for $2 \mathrm{~h}$, the reaction was stopped with trichloroacetic acid (TCA) $5 \%$ on ice, following incubation at $4^{\circ} \mathrm{C}$ for $1 \mathrm{~h}$. The mixture was centrifuged at $4000 \mathrm{~g}$ for $10 \mathrm{~min}$ at $4^{\circ} \mathrm{C}$. After this, three aliquots $(150$ $\mu \mathrm{l}$ each) of the reaction mixture were transferred to wells on a microtiter plate containing $100 \mu \mathrm{l}$ of a Coomassie solution $(0.025 \%$ Coomassie brilliant blue G-250, $11.75 \%$ ethanol, and $21.25 \%$ phosphoric acid). After 10 min to allow dye binding, the plate was read on an Asys HiTech UVM 340 microplate reader at an absorbance of $595 \mathrm{~nm}$. Protease activity was calculated based on the absorbance difference between samples and controls. The control samples were added supernatants that were immediately treated with TCA. One unit (U) of proteolytic activity was defined as the amount of enzyme that caused an increase of 0.001 in absorbance unit, under standard assay conditions. The proteolytic activity is expressed as $\mathrm{U} / \mathrm{ml}$

\subsection{Scanning Electron Microscopy}

To verify the adhesion pattern of yeast cells with human keratin substrates, samples were fixed in $2.5 \%$ glutaral- 
dehyde (Electron Microscopy Sciences) in $0.1 \mathrm{M}$ phosphate buffer, $\mathrm{pH} 7.2$, followed by incubation at $4^{\circ} \mathrm{C}$ for $18 \mathrm{~h}$. Then, the samples were carefully washed with 0.1 $\mathrm{M}$ phosphate buffer, $\mathrm{pH}$ 7.2. Post-fixation was carried out for $1 \mathrm{~h}$ at $25^{\circ} \mathrm{C}$ with $1 \%$ osmium tetroxide in $0.1 \mathrm{M}$ phosphate buffer. Samples were gently dehydrated in graded ethanol, critical point-dried in $\mathrm{CO}_{2}$ (BALTEC DCP 030 Critical Point Dryer), coated with gold (BALTEC SDC 050 Sputter Coater) and viewed in a FEI Quanta 200 Scanning Electron Microscope.

\subsection{Statistical Analysis}

All the experiments were repeated three times and assay was performed in duplicate. Tukey test was used to determine statistical significance. $P<0.05$ was considered statistically significant.

\section{Results and Discussion}

\subsection{In Vitro Adherence Pattern of C. parapsilsois Cells to Human Keratinous Substrates}

Yeast pathogenicity arises through complex interactions between the organism's virulence characteristics and the host's response. Compared with C. albicans, little is specifically known regarding virulence factors in C. parapsilosis sensu stricto.

Adherence is essential for members of the genus Candida to develop their pathogenic potential since it triggers the process that leads to colonization and allows their persistence in the host. For instance, more pathogenic Candida isolates showed higher adherence capacity on human oral and epithelial cells [21]. According to these authors, epithelial cell variability played a critical role in the adherence phenomenon [21].

In our study, we analysed the in vitro pattern of adherence of C. parapsilosis sensu stricto cells to human keratinised substrates, i.e., on soft keratin (cutaneous stratum corneum - the outermost layer of skin) and hard keratin (nail and hair). By scanning electron microscopy it was observed that all C. parapsilosis isolates adhered to the keratinous substrates (Figure 1). On hair fragments, the adherent cells are seen only within the follicle cortex and the number of cells adhered to this substrate varied among isolates (Figure 1(c)).
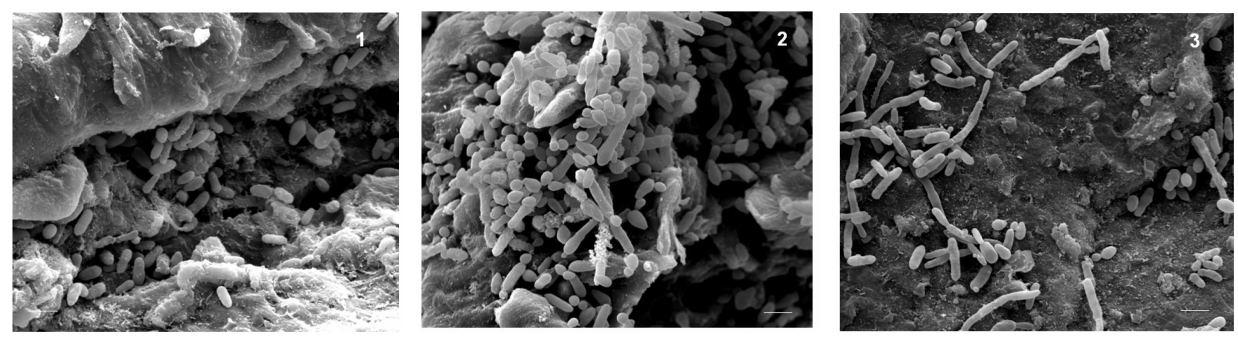

(a)
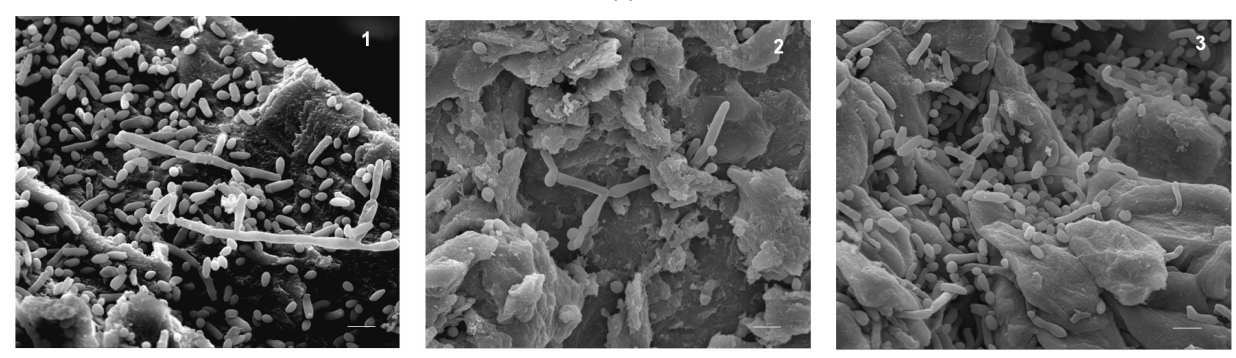

(b)
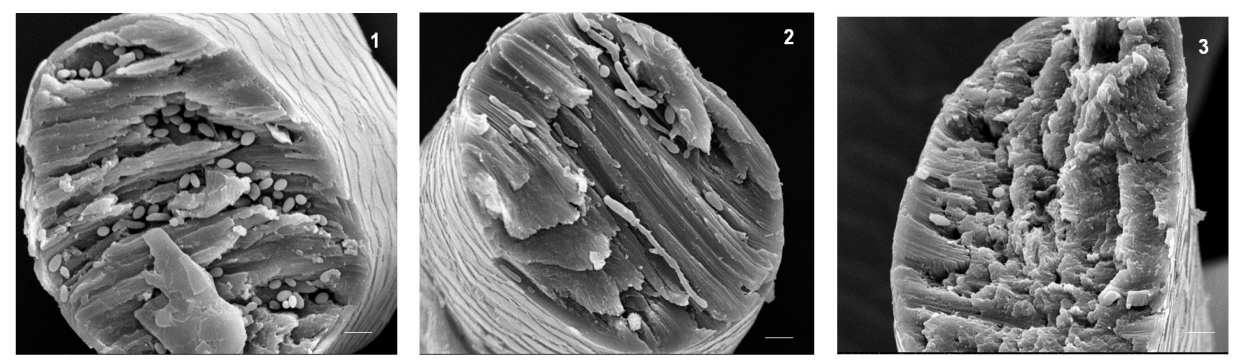

(c)

Figure 1. Electron micrographs showing the in vitro adherence pattern of Candida parapsilsois cells to human keratinous substrates. (a) Stratum corneum, (b) Nail and (c) Hair. (1) Isolate 150.06, (2) Isolate 220.07 and (3) Isolate 205.06. Magnification of $3000 \times$. Extracellular material (arrows) is seeing evolving cells from the isolate 150.06 (a1). 
SEM analysis revealed that the onychomycoses isolate presented different morphological pattern according to the substrate that they were in contact. For instance, cells adhered to stratum corneum and hair keratin consisted mainly of cells in the budding-yeast phase of growth (blastoconidia) (Figures 1(a1) and (c1)). Differently, on nail keratin pseudohyphae production was observed (Figure 1(b1)), a pattern that could indicate that this situation favours cellular morphologies with capacity for tissue invasion. This data extend our previous observation that different profiles of biofilm formation by C. parapsilosis occurred as function of the keratinous substrate [9].

For the other isolates the cellular population consisted of blastoconidia and pseudohyphae on all substrates analysed, with exception of the isolate 205.06 (tracheal secretion) on hair keratin (Figure 1(c3)). Intraspecific differences in adherence to polystyrene have been described among clinical isolates of $C$. parapsilosis obtained from distinct body sites [12]. More recently, reconstituted human epithelium (RHE) has been used to study in vitro colonization by $C$. parapsilosis complex [13,14]. According to these authors, the extent of surface colonization on RHE by C. parapsilosis was strain dependent.

Overall, there was a loose association between yeast cells and keratinous substrates. However, on stratum corneum flocculent extracellular material was seen evolving cells from the onychomycoses isolate by forming a biofilm-like structure (Figure 1(a1)). This feature was not observed on the other two sources of human keratin (nail and hair).

It has been showed that adhesion [22] and ability to grow as biofilms [23] on abiotic surfaces are especially important for outbreaks of C. parapsilosis infections (reviewed in Trofa et al. [4]). This is the first report of ultrastructural features related to adhesion of C. parapsilosis isolates associated with skin and nail infections to distinct keratinised substrates from human source.

\subsection{Acid Proteinases Production}

In this study, we evaluated for the first time the growth profile and the production of acid proteinases by $C$. parapsilosis using human keratin as sole source of nitrogen. The isolates tested presented similar trend of growth rate in keratin-supplemented media. However, the fungal growths were more profusely in stratum corneum-supplemented medium than in hair- and nail-supplemented medium (cell density reached $10^{8}$ cells $/ \mathrm{ml}$ and $10^{7}$ cells $/ \mathrm{ml}$, respectively), probably due to differences in keratin structure and the degree of cross-linkages by disulfide and hydrogen bonds.

The results obtained (Figure 2) showed that C. parapsilosis sensu stricto isolates produced proteinases in all tested media. The isolate recovered from onychomycosis

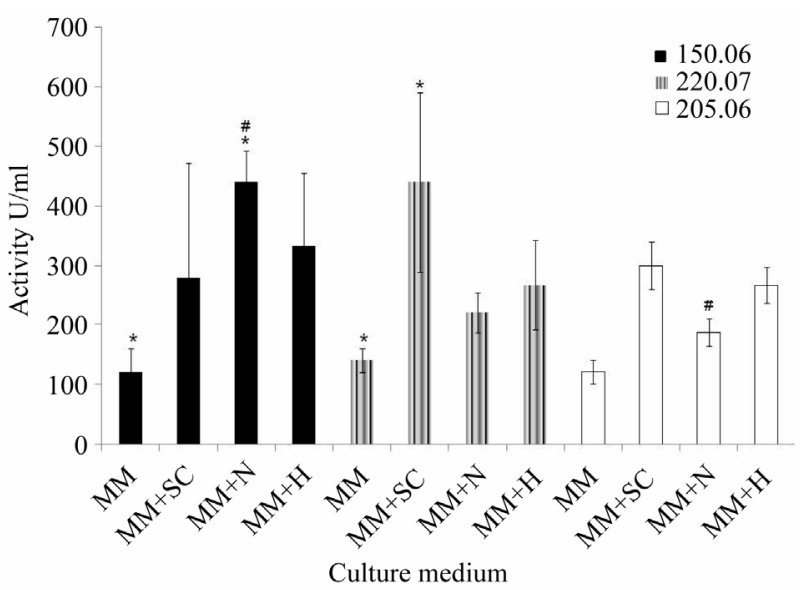

Figure 2. Measurement of secreted acid proteinase activity on haemoglobin in clinical isolates of Candida parapsilosis obtained from onychomycosis (150.06), cutaneous candidiasis (220.07) and tracheal secretion (205.06). After growth in basal minimal medium (MM) and MM supplemented with stratum corneum (MM + SC), MM supplemented with hair $(\mathbf{M}+\mathbf{H})$ and $\mathrm{MM}$ supplemented with nail $(\mathrm{MM}+\mathbf{N})$ for $10 \mathrm{~d}$ at $37^{\circ} \mathrm{C}$, the cultures were harvested and the spent culture media were then tested to degrade soluble haemoglobin. The proteolytic activity was determined as described in Material and methods and is reported as arbitrary units $(\mathrm{U} / \mathrm{ml})$. Standard errors of the means for three measurements are presented as bars. ${ }^{*} \mathbf{P}<\mathbf{0 . 0 5}$ for $\mathbf{M M}+\mathbf{N}$ vs $\mathbf{M M}$ (isolate 150.06) and MM + SC vs MM (isolate 220.07). ${ }^{\neq} \mathbf{P}<$ 0.05 for isolate 150.06 vs 205.06 (MM + N medium).

produced higher amount of acid proteinases $(\mathrm{P}<0.05)$ in medium supplemented with nail keratin $(440 \mathrm{U} / \mathrm{ml})$ than in salt medium (absence of keratin) $(120 \mathrm{U} / \mathrm{ml})$. No differences $(\mathrm{P}>0.05)$ were observed on proteinase production in the presence of the other two sources of keratin (stratum corneum and hair). For the isolate 220.07 (cutaneous lesion) the production of acid proteinases was higher in medium supplemented with stratum corneum keratin $(440 \mathrm{U} / \mathrm{ml})$ than in salt medium $(120 \mathrm{U} / \mathrm{ml})$ (Figure 2). These data suggest that the source of keratin seems to be correlated to the induction of acid proteinases in an isolate dependent manner.

Differently, no differences were observed in the amount of acid proteinases produced by the isolate recovered from tracheal secretion in the media tested (absence and presence of keratin substrates) (Figure 2). Furthermore, when compared proteinase production by Candida isolates after growth in the same source of keratin, e.g., in nail keratin medium, the isolate recovered from onychomycosis exhibited higher proteinase activity $(\mathrm{P}<0.05)$ than isolate obtained from tracheal secretion, suggesting that the potential of $C$. parapsilosis nail isolate to cause onychomycoses may be associated with acid proteinase production.

It has been reported that the expression of genes en- 
coding aspartic proteinases (Saps) varied among different clinical isolates of $C$. parapsilosis complex when grown in contact with human oral epithelium [14]. According to these authors there is a trend relating Sap production and site of isolates recovering.

In C. albicans, the most discussed hydrolytic enzymes are secreted aspartic proteinases (Saps), which are one of the well-known virulence factors of this species (reviewed in Schaller et al. [24]). According to Monod and Borg-von [25] Saps play a role in fungal adherence and invasion of skin by C. albicans. The occurrence of Saps has been previously demonstrated in C. parapsilosis isolates obtained from distinct clinical samples [10,26-28] and it has being suggested that Saps are associated in superficial, but not with systemic invasion, caused by $C$. parapsilosis [26]. They observed the induction of Saps from $C$. parapsilosis cultivated in media containing bovine serum albumin (BSA) as a nitrogen source. Considering the clinical point view, it is questionable whether these enzymes could have the required function of digesting keratinised tissue for parasitism. Recently we showed that the production of Saps, in BSA inducing medium, by C. parapsilosis isolates obtained from nail and skin was less expressive compared to isolates obtained from blood and tracheal secretion [10]. Although it has been established that C. parapsilosis is an opportunistic pathogen related to the skin surface, and is also emerging as an important cause of onychomycosis, as far we know, in the present study we describe for the first time the production of acid proteases by isolates of $C$. parapsilosis recovered from superficial mycoses in the presence of keratinous substrates obtained from human sources. Nevertheless, the properties of the individual proteins that presumably account for the virulence of $C$. parapsilosis have not yet been elucidated to date.

\section{Conclusion}

In conclusion, ultrastructural investigations of the interface of $C$. parapsilosis and the keratinised substrates from human source reveal important features, which may help to clarify the pathogenesis of superficial candidiasis. Our findings indicate the need for investigation of a possible involvement of acid proteinase in the onychomycosis and cutaneous lesion due to this species.

\section{Acknowledgements}

This work was supported by Conselho Nacional de Desenvolvimento Científico e Tecnológico (CNPq) - Brazil, Fundação Araucária-Paraná-Brazil and PROPPG/UELBrazil. A.F.L.S. was fellowship-holder of Coordenação de Aperfeiçoamento de Pessoal de Nível Superior (CAPES)-Brazil.

\section{REFERENCES}

[1] F. M. V. Lunel, J. F. G. M. Méis and A. Voss, "Nosocomial Fungal Infections: Candidemia," Diagnostic Microbiology and Infectious Disease, Vol. 34, No. 3, 1999, pp. 213-220.

http://dx.doi.org/10.1016/S0732-8893(99)00035-8

[2] L. Saiman, E. Ludington and J. Dawson, "Risk Factors for Candida Species Colonization of Neonatal Intensive Care Unit Patients," Pediatric Infectious Diseases Journal, Vol. 20, No. 12, 2001, pp. 1119-1124. http://dx.doi.org/10.1097/00006454-200112000-00005

[3] E. C. van Asbeck, K. V. Clemins and D. A. Stevens, "Candida parapsilosis: A Review of Its Epidemiology, Pathogenesis, Clinical Aspects, Typing and Antimicrobial Susceptibility," Critical Reviews in Microbiology, Vol. 35, No. 4, 2009, pp. 283-309.

http://dx.doi.org/10.3109/10408410903213393

[4] D. Trofa, A. Gácser and J. D. Nosanchuk, "Candida parapsilosis: An Emerging Fungal Pathogen," Clinical Microbiology Reviews, Vol. 21, No. 4, 2008, pp. 606-625. http://dx.doi.org/10.1128/CMR.00013-08

[5] R. S. N. Brilhante, R. A. Cordeiro, D. J. A. Medrano, M. F. G. Rocha, A. J. Monteiro, C. S. P. Cavalcante, T. E. F. Meireles and J. J. C. Sidrim, "Onychomycosis in Ceará (Northeast Brazil): Epidemiological and Laboratory Aspects," Memórias do Instituto Oswaldo Cruz, Vol. 100, No. 2, 2005, pp. 131-135. http://dx.doi.org/10.1590/S0074-02762005000200005

[6] A. C. Oliveira, C. S. Shinobu, R. Longhini, S. L. Franco and T. I. E. Svidzinski, "Antifungal Activity of Propolis Extract against Yeasts Isolated from Onychomycosis Lesions," Memórias do Instituto Oswaldo Cruz, Vol. 101, No. 5, 2006, pp. 493-497. http://dx.doi.org/10.1590/S0074-02762006000500002

[7] V. T. Figueiredo, D. A. Santos, M. A. Resende and J. S. Hamdan, "Identification and in Vitro Antifungal Susceptibility Testing of 200 Clinical Isolates of Candida spp. Responsible for Fingernail Infections," Mycopathologia, Vol. 164, No. 1, 2007, pp. 27-33.

http://dx.doi.org/10.1007/s11046-007-9027-6

[8] E. A. Martins, L. V. Guerrer, K. C. Cunha, M. M. C. Soares and M. T. G. Almeida, "Onychomycosis: Clinical, Epidemiological and Mycological Study in the Municipality of São José do Rio Preto," Revista da Sociedade Brasileira de Medicina Tropical, Vol. 40, No. 5, 2007, pp. 596-598.

http://dx.doi.org/10.1590/S0037-86822007000500022

[9] M. T. Oliveira, A. F. L. Specian, C. G. T. J. Andrade, E. J. G. França, L. Furlaneto-Maia and M. C. Furlaneto, "Interaction of Candida parapsilosis Isolates with Human Hair and Nail Surfaces Revealed by Scanning Electron Microscopy Analysis," Micron, Vol. 41, No. 6, 2010, pp. 604-608. http://dx.doi.org/10.1016/j.micron.2010.03.011

[10] E. J. G. França, L. Furlaneto-Maia, R. M. B. Quesada, D. Favero, M. T. Oliveira and M. C. Furlaneto, "Haemolytic and Proteinase Activities in Clinical Isolates of Candida parapsilosis and Candida tropicalis with Reference to the Isolation Anatomic Site," Mycoses, Vol. 54, No. 4, 2010, pp. e44-e51. 
http://dx.doi.org/10.1111/j.1439-0507.2009.01825.x

[11] D. Favero, L. Furlaneto-Maia, E. J. G. França, H. P. Góes and M. C. Furlaneto, "Hemolytic Factor Production by Clinical Isolates of Candida Species," Current Microbiology, 2013. http://dx.doi.org/10.1007/s00284-013-0459-6

[12] A. Sanchez-Sousa, D. Tarrago, J. Velasco, M. E. Alvarez and F. Baquero, "Adherence to Polystyrene of Clinically Relevant Isolates of Candida Species," Clinical Microbiology and Infection, Vol. 7, No. 7, 2001, pp. 379-382. http://dx.doi.org/10.1046/j.1198-743x.2001.00266.x

[13] A. Gácser, W. Schafer, J. S. Nosanchuk, S. Salomon and J. D. Nosanchuk, "Virulence of Candida parapsilosis, Candida orthopsilosis, and Candida metapsilosis in Reconstituted Human Tissue Models," Fungal Genetics and Biology, Vol. 44, No. 12, 2007, pp. 1336-1341. http://dx.doi.org/10.1016/j.fgb.2007.02.002

[14] S. Silva, M. Henriques, R. Oliveira, J. Azeredo, S. Malic, S. L. Hooper and D. W. Williams, "Characterization of Candida parapsilosis Infection of an in Vitro Reconstituted Human Oral Epithelium," European Journal of Oral Sciences, Vol. 117, No. 6, 2009, pp. 669-675. http://dx.doi.org/10.1111/j.1600-0722.2009.00677.x

[15] M. C. Furlaneto, J. F. Rota, R. M. B. Quesada, L. Furlaneto-Maia, R. Rodrigues, S. Oda, M. T. Oliveira, R. Serpa and E. J. G. França, "Species Distribution and in Vitro Fluconazole Susceptibility of Clinical Candida Isolates in a Brazilian Tertiary-Care Hospital over a 3-Year Period," Revista da Sociedade Brasileira de Medicina Tropical, Vol. 44, No. 5, 2011, pp. 595-599. http://dx.doi.org/10.1590/S0037-86822011000500013

[16] A. Tavanti, A. D. Davidson, N. A. R. Gow, M. C. J. Maiden and F. C. Odds, "Candida orthopsilosis and Candida metapsilosis spp. nov. to Replace Candida parapsilosis Groups II and III," Journal of Clinical Microbiology, Vol. 43, No. 1, 2005, pp. 284-292. http://dx.doi.org/10.1128/JCM.43.1.284-292.2005

[17] H. Gradisar, S. Kern and J. Friedrich, "Keratinase of Doratomyces microsporus," Applied Microbiology and Biotechnology, Vol. 53, No. 2, 2000, pp. 196-200. http://dx.doi.org/10.1007/s002530050008

[18] J. Friedrich, H. Gradisar, D. Mandin and J. P. Chaumont, "Screening Fungi for Synthesis of Keratinolytic Enzymes," Letters in Applied Microbiology, Vol. 28, No. 2, 1999, No. 2, pp. 127-130.

[19] M. A. El-Naghy, M. S. El-Ktatny, E. M. Fadl-Allah and W. W. Nazeer, "Degradation of Chicken Feathers by Chrysosporium georgiae," Mycopathologia, Vol. 143, No.
2, 1998, pp. 77-84. http://dx.doi.org/10.1023/A:1006953910743

[20] A. L. S. Santos, I. M. Carvalho, B. A. Silva, M. B. Portela, C. S. Alvino and R. M. A. Soares, "Secretion of Serine Peptidases by a Clinical Strain of Candida albicans: Influence of Growth Conditions and Cleavage of Human Serum Proteins and Extracellular Matrix Components," FEMS Immunology and Medical Microbiology, Vol. 46, No. 2, 2006, pp. 209-220.

http://dx.doi.org/10.1111/j.1574-695X.2005.00023.x

[21] R. D. King, J. C. Lee and A. L. Morris, "Adherence of Candida albicans and Other Species to Mucosal Epithelial Cells," Infection and Immunity, Vol. 27, No. 2, 1980, pp. 667-674.

[22] D. M. Kuhn, J. Chandra, P. K. Mukherjee and M. A. Ghannoum, "Comparison of Biofilms Formed by Candida albicans and Candida parapsilosis on Bioprosthetic Surfaces," Infection and Immunity, Vol. 70, No. 2, 2002, pp. 878-888. http://dx.doi.org/10.1128/IAI.70.2.878-888.2002

[23] D. M. Kuhn, P. K. Mukherjee and T. A. Clark, "Candida parapsilosis Characterization in an Outbreak Setting," Emerging Infectious Diseases, Vol. 10, No. 6, 2004, pp. 1074-1081. http://dx.doi.org/10.3201/eid1006.030873

[24] M. Schaller, C. Borelli, H. C. Korting and B. Hube, "Hydrolytic Enzymes as Virulence Factors of Candida albicans," Mycoses, Vol. 48, No. 6, 2005, pp. 365-377. http://dx.doi.org/10.1111/j.1439-0507.2005.01165.x

[25] M. Monod and Z. M. Borg-von, "Secreted Aspartic Proteases as Virulence Factors of Candida Species," Biological Chemistry, Vol. 383, No. 7-8, 2002, pp. $1087-$ 1093. http://dx.doi.org/10.1515/BC.2002.117

[26] F. De Bernardis, F. Mondello, R. San Millàn, J. Ponón and A. Cassone, "Biotyping and Virulence Properties of Skin Isolates of Candida parapsilosis," Journal of Clinical Microbiology, Vol. 37, No. 11, 1999, pp. 3481-3486.

[27] M. Dagdeviren, N. Cerikcioglu and M. Karavus, "Acid Proteinase, Phospholipase and Adherence Properties of Candida parapsilosis Strains Isolated from Clinical Specimens of Hospitalized Patients," Mycoses, Vol. 48, No. 5, 2005, pp. 321-326. http://dx.doi.org/10.1111/j.1439-0507.2005.01145.x

[28] A. Tavanti, L. A. M. Hensgens, S. Mogavero, L. Majoros, S. Senesi and M. Campa, "Genotypic and Phenotypic Properties of Candida parapsilosis Sensu Strictu Strains Isolated from Different Geographic Regions and Body Sites," BMC Microbiology, Vol. 10, 2010, pp. 2-11. http://dx.doi.org/10.1186/1471-2180-10-203 